\title{
Fatigue Crack Inspection and Acoustic Emission Characteristics of Precast RC Beam under Repetition Loading
}

\author{
NOORSUHADA Md Nor ${ }^{1,2, a}$, AZMI Ibrahim², \\ NORAZURA Muhamad Bunnori ${ }^{3}$, HAMIDAH Mohd Saman ${ }^{2}$, \\ SOFFIAN NOOR Mat Saliah ${ }^{1}$ and SHAHIRON Shahidan ${ }^{4}$ \\ ${ }^{1}$ Faculty of Civil Engineering, Universiti Teknologi MARA, 13500 Permatang Pauh, Pulau Pinang, \\ Malaysia \\ ${ }^{2}$ Faculty of Civil Engineering, Universiti Teknologi MARA, 40450 Shah Alam, Selangor, Malaysia. \\ ${ }^{3}$ School of Civil Engineering, Engineering Campus, Universiti Sains Malaysia, Seri Ampangan, \\ Seberang Perai Selatan, 14300 Nibong Tebal, Pulau Pinang, Malaysia. \\ ${ }^{4}$ Fakulti Kejuruteraan Awam dan Alam Sekitar, Universiti Tun Hussein Onn Malaysia, 86400 Batu \\ Pahat, Johor, Malaysia. \\ aidanur211@gmail.com/ida_nsn@ppinang.uitm.edu.my
}

Keywords: fatigue crack; repetition loading; acoustic emission; signal strength

\begin{abstract}
Fatigue crack of the precast reinforced concrete beam under repetition loading is vital to be examined. Reinforced concrete structures exposed to excessive repetition loading could lead to the failure of the structures. In order to examine the active fatigue crack, the reinforced concrete beams were subjected to three-point repetition maximum loading. Eight phases of maximum fatigue loading with sinusoidal wave, frequency of $1 \mathrm{~Hz}$ and 5000 cycles for each phase were performed on the reinforced concrete beams. The inspection was carried out with visual observation of the crack pattern and acoustic emission technique for each load phase. The signal strength of acoustic emission was investigated. It is found that the signal strength of acoustic emission and crack pattern of the reinforced concrete beam subjected to repetition loadings showed promising results for structural health monitoring.
\end{abstract}

\section{Introduction}

Fatigue is a process of progressive localized permanent structural change in a material subjected to repetitive loading. Many structures such as bridges, dams and buildings often experience repetitive loads. Exposure of repetitive loads may result in fatigue failure. Before reaching the fatigue failure, it needs to the inspection of the fatigue behaviour such as fatigue crack that occurs in a structure. The inspection can be done by using a non-destructive testing (NDT) such as acoustic emission (AE) technique. $\mathrm{AE}$ is able to monitor crack formation and propagation that occur in reinforced concrete (RC) structure [1]. At the same time, the integrity of the RC structure can be monitored [2,3]. The application of $\mathrm{AE}$ in fatigue of $\mathrm{RC}$ structure has been previously reported by several researchers [4-6]. The AE activity of reinforced concrete and prestressed concrete beam under cyclic loading has been investigated by Shield [6]. The crack initiation and crack propagation due to bending were monitored using $\mathrm{AE}$ and compared with visual observation. He found that the crack was preceded by a significant increase of $\mathrm{AE}$ activity. The monitoring of $\mathrm{AE}$ is able to determine the active crack growth in RC structures.

The fatigue crack can be assessed using the analysis of AE signal based on its parameter such as signal strength. The signal strength is one of the AE energies. It is defined as "the measured area of the rectified AE signal with units proportional to volt-second" [7] which normally include the absolute area of both positive and negative envelopes [8]. The AE signal strength is found to be closely related with the amount energy released [1]. High of the signal strength is normally related with damage development in a structure [5]. It is also can be used for evaluation of damage process and integrity of prestressed concrete structure [1] and determination of AE onset on fibre reinforced 
vessel [8]. Md Nor et al. [5] have used the AE signal strength for determination of early onset of crack growth in $\mathrm{RC}$ beam subjected to constant fatigue amplitude. At the same time, the higher value of $\mathrm{AE}$ signal strength represents the failure stage of the $\mathrm{RC}$ beam specimen. $\mathrm{Xu}$ [1] enhanced that the formation and propagation of visible cracks can be identified by the increase of AE signal strength.

In most cases, the $\mathrm{AE}$ characteristics increased as the load increased when single fatigue amplitude was applied for each load phase [4]. A question is raised whether the same phenomenon would occur if the replicate loads are applied to the beam specimen with the same load cycles. Is the second load phase would generate the same AE characteristics as that of previous phase of load? The AE characteristic of beam subjected to repeating fatigue load cycle has not been reported elsewhere. In present study, the repetitive maximum fatigue loading was used in order to investigate the AE characteristics and crack pattern on the beam specimen when replicate loads in two times was applied.

\section{Experimental Programme}

Five precast RC beams of $300 \mathrm{~mm}$ x $600 \mathrm{~mm}$ x $4050 \mathrm{~mm}$ were cast using concrete grade 40 . Ready mix concrete was used to all specimens with different proportions by weight of cement: water: fine aggregate: coarse aggregate and it was 1.00: 0.45: 2.07: 2.74, respectively. In order to improve the workability of the fresh concrete, $0.8 \%$ of admixture (superplasticiser) of cement weight was added in the concrete mix. The concrete was reinforced using high strength steel of $460 \mathrm{~N} / \mathrm{mm}^{2}$. The average compressive strength of core samples is $42.74 \mathrm{~N} / \mathrm{mm}^{2}$. Fig. 1a depicts the configuration of maximum fatigue load, $\mathrm{P}_{\max }$ applied to the beam specimens. Two replicates of load phases were applied which based on first load crack, $\mathrm{P}_{\text {cr }}$ and ultimate static load, $\mathrm{P}_{\text {ult }}$ as shown in Fig 1a. The $\mathrm{P}_{\text {cr }}$ is $51 \mathrm{kN}$ and the $\mathrm{P}_{\text {ult }}$ determined of $332.31 \mathrm{kN}$ [4]. The behaviour of beam specimen with respect to $\mathrm{AE}$ activities under these loads was investigated. After PII8, the beam specimen was statically loaded to failure.
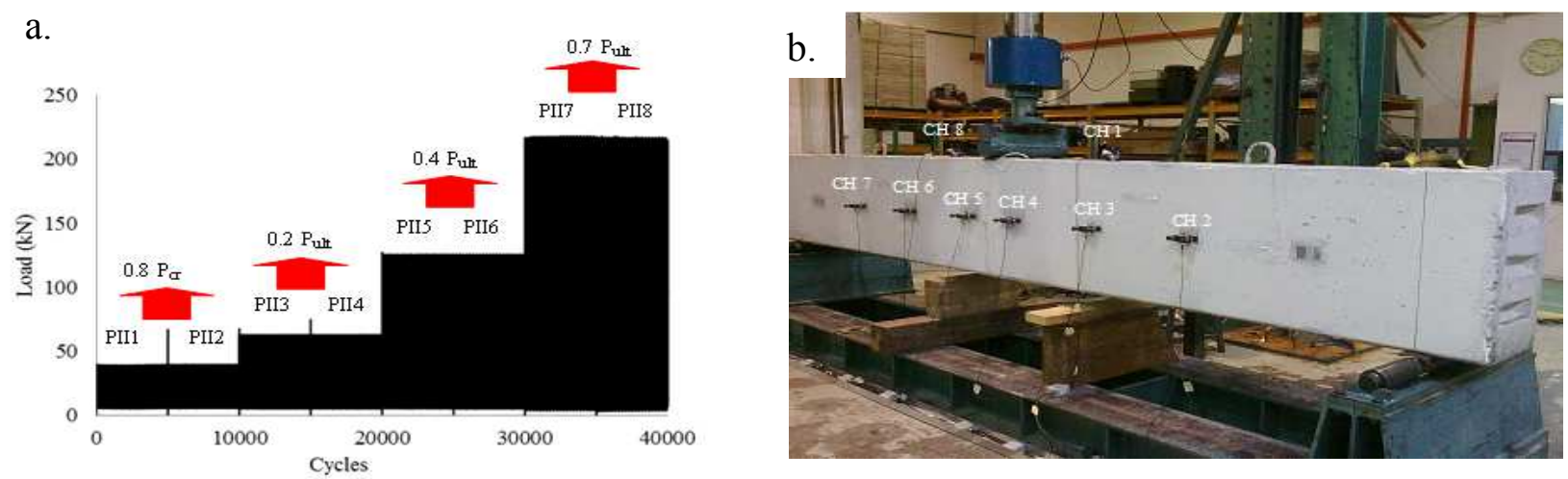

Fig. 1a. Fatigue load protocol applied to precast RC beam specimen $\mathrm{b}$. Test setup and location of sensors on precast RC Beam Specimen Subjected to third-point load

Third point load as shown in Fig. 1b was performed using a servo-hydraulic testing machine on the precast $\mathrm{RC}$ beam in conjunction with $\mathrm{AE}$ monitoring. The fatigue test was performed using sine wave load cycle with frequency of $1 \mathrm{~Hz}$. Each load phase, the beam was loaded with 5000 fatigue cycles. Minimum fatigue load, $\mathrm{P}_{\min }$ of $5 \mathrm{kN}$ was applied throughout the testing. In order to monitor the crack behaviour, the visual observation was also carried out to confirm the invisibility of the cracks [4]. The arrangement of the sensors on the beam surface is depicted in Fig. 1b. The sensor locations were set as planar plane. High performance grease was used to couple the sensors surface and the beam surface. The wave velocity $4000 \mathrm{~m} / \mathrm{s}$, rearm time $1.62 \mathrm{~ms}$, duration discrimination time $400 \mu \mathrm{s}$, pre-trigger samples 200 , threshold $45 \mathrm{~dB}$ and sample rate $10 \mathrm{MHz}$ were set prior to the AE monitoring carried out. 


\section{Results and Discussion.}

Fatigue Crack Inspection. From visual inspection, it is found that no crack was observed under load in PII1 and PII2 with the $\mathrm{P}_{\max }$ of $0.8 \mathrm{P}_{\mathrm{cr}}$. It indicates that this load did not impose stress to the beam and therefore no high stress beam specimen is evident.
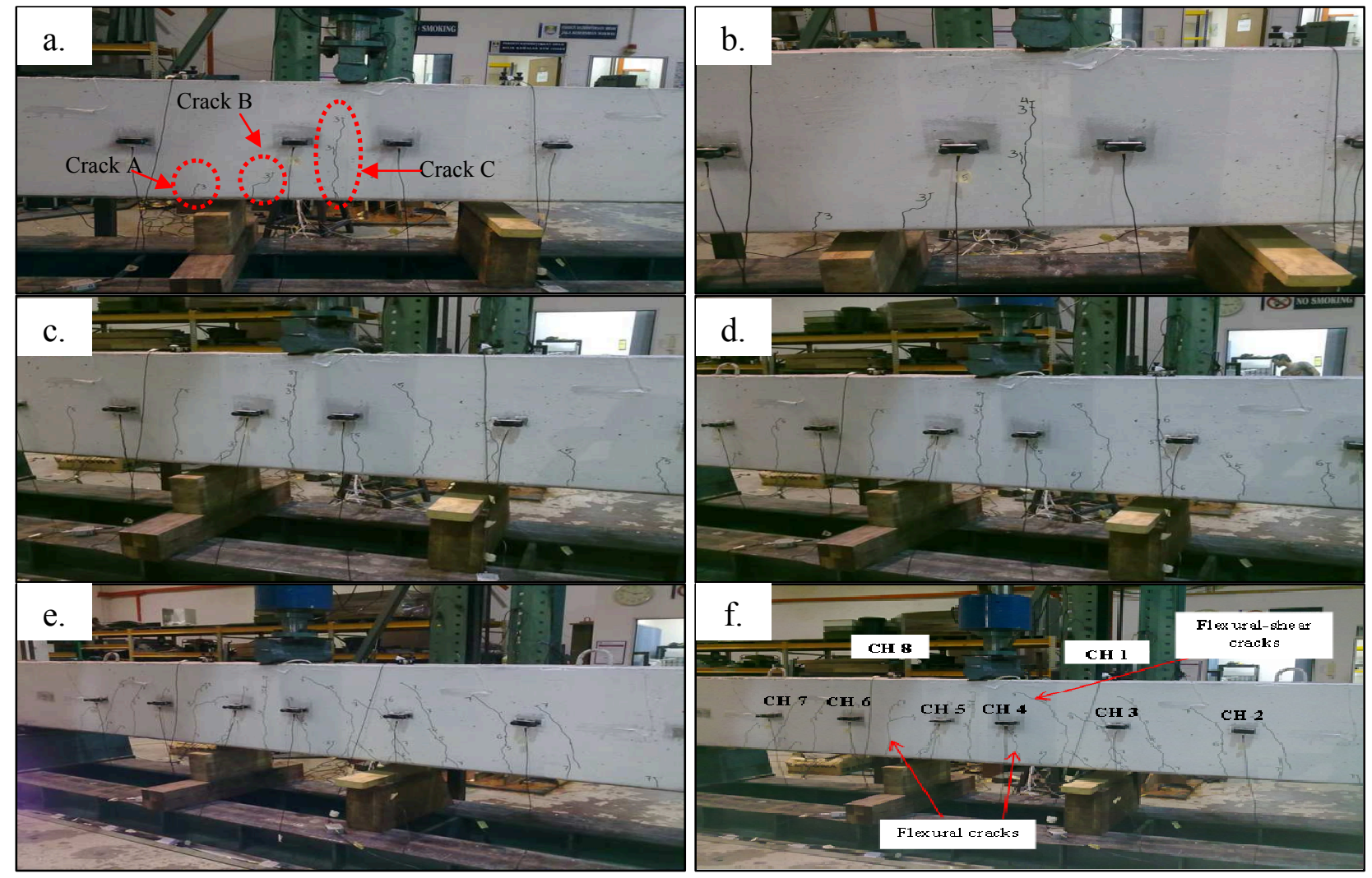

Fig. 2. Crack pattern of the beam specimen subjected to a. $0.2 \mathrm{P}_{\text {ult }}(\mathrm{PII} 3) \mathrm{b}$. repeating $0.2 \mathrm{P}_{\text {ult }}(\mathrm{PII} 4)$ c. $0.4 \mathrm{P}_{\text {ult }}$ (PII5) d. repeating $0.4 \mathrm{P}_{\text {ult }}$ (PII6) e. $0.7 \mathrm{P}_{\text {ult }}$ (PII7) f. repeating $0.7 \mathrm{P}_{\text {ult }}$ (PII8)

The cracks were generated when the beam specimen was subjected to PII3 as shown in Fig. 2a. Three cracks were inspected with the longer one at the mid-span of the beam and noted as Cracks A, B and C. Cracks A, B and C was located at $1.58 \mathrm{~m}, 1.78 \mathrm{~m}$ and $2.02 \mathrm{~m}$ from the edge of the beam on the left as shown in Fig. 1a, respectively. Crack marked Number 4 as depicted in Fig. 2b appears when load PII4 was applied on the beam specimens. It is found that the crack length increased when the same load as previous phase was reapplied on the beam. Many new cracks were noticed during the application of PII5 as shown in Fig. 2c. A tremendous increase in number of crack was noticed when the intensity of load increased in double than the previous load. The beam specimen experiences crack, however, in small number when the same fatigue amplitude was applied. This crack occurred as first few cycles of loading were applied which imposed the stress to the beam. The same phenomenon was observed as the beam was subjected to PII6 loading when the same load as previous phase was repeatedly applied as shown in Fig. $2 \mathrm{~d}$. The crack development continues as the fatigue maximum load increased to PII7 as illustrated in Fig. 2e. Most of the new cracks developed in the shear section. They are propagated initially with flexural crack and then run with angles of about $45^{\circ}$ which probably start at the end of the flexure crack. McCormac and Nelson [9] stated that the vertical flexural cracks are not dangerous unless shear stress and flexure stress combination occurs at the top of one of the flexure crack. The cracks are known as flexure-shear crack. As the cracks move up to the neutral axis, the shear stress increases on the concrete above the crack [9]. The cracked concrete would not resist the shear as fatigue load continues. However, due to the presence of reinforcing bars, the shear stresses are transferred to the bars. The reinforcing bars 
keep the cracks from becoming larger and enable the concrete to transfer shear across the cracks by aggregate interlocking [9]. The increase of crack as PII8 of the repetitive loading was applied minimally as compared to previous crack that appeared in PII7 loading at the same maximum fatigue load. It can be shown in Fig. 2f. For this beam specimen which considered as long span, it is found that the concentration of crack at high load started at about $0.4 \mathrm{~m}$ away from support at both sides of the beam specimen. The beam fails in bending since many flexural cracks occur.

Acoustic Emission Characteristics. Fig. 3a shows the AE characteristics generated when the beam specimen was subjected to $0.8 \mathrm{P}_{\mathrm{cr}}$ (PII1). It is found that the signal strength is very low at this load phase. The highest signal strength of $1010 \mathrm{nVs}$ was noticed at the location $2.05 \mathrm{~m}$ from the edge. It indicates that the crack was initiated. Hence, the AE characteristic corresponding to this load phase provides useful information on the crack initiation in the beam specimen. When the same load of $0.8 \mathrm{P}_{\mathrm{cr}}$ was repeated in PII2 loading for the same load cycles, it seemingly indicates that there is no increase in signal strength as depicted in Fig. 3b. In order to show the increment of AE signal when the beam was subjected to PII1 and PII2 loadings for the same load of $0.8 \mathrm{P}_{\text {cr }}$, events for each load phase are calculated. Different between PII1 and PII2 is 7616 events. It exhibits the generation of AE signal increased when load PII2 was applied.
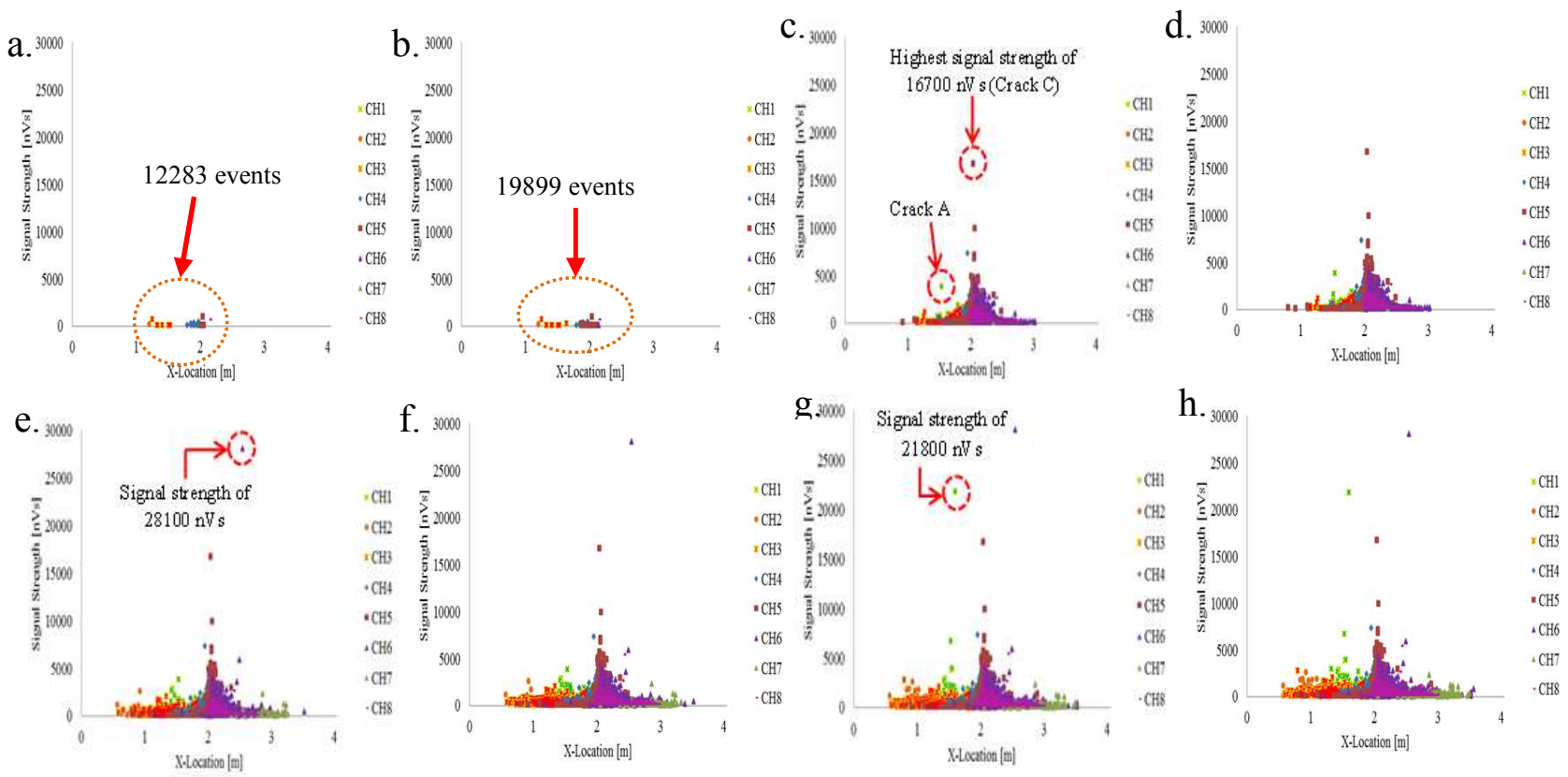

Fig. 3 AE signal strength with respect to X-location when the beam specimen subjected to a. PII $1 \mathrm{~b}$. PII2 c. PII3 d. PII4 e. PII5 f. PII6 g. PII7 h. PII8

The crack pattern in PII3 loading as shown in Fig. 2a is matched with AE characteristic generated when the beam specimen subjected to the repeated load of PII2, it is confirmed that the crack occurrence is well corresponding to the highest value of signal strength in Fig. 3c. It indicates the AE characteristic can be used to predict crack occurrence. As the crack appears on the beam surface as shown in Fig. 2a, the AE generates scattered signal with the highest concentration at the midspan as shown in Fig. 3c. The highest signal strength is found to be $16700 \mathrm{nVs}$ at $2.05 \mathrm{~m}$ from the edge. It indicates that $\mathrm{CH} 5$ received the first wave released by the cracks with the high signal. These AE characteristics represent the crack occurrence at point C. Since Crack A is almost vertically propagated, signal strength of $3850 \mathrm{nVs}$ at $1.54 \mathrm{~m}$ of distance from the edge represents this crack. Although the crack increment is small when repeating load of $0.2 \mathrm{P}_{\mathrm{ult}}$ (PII4) was applied on the beam specimen, the AE signals captured as presented in Fig. 3d increased with the low AE signals. The AE events collected within the application of both phases were computed. The total of AE events collected during the application PII3 loading is 12283 events and PII4 loading is 19899 events. It 
shows that the AE signal strength increased as the load intensity increases. Fig. 3e shows the AE parameters in terms of signal strength collected as loading of PII5 was applied to the beam specimen. The AE signal is more intense along the X-location of $0.59 \mathrm{~m}$ to $3.53 \mathrm{~m}$ from the edge, which is within the area where cracks actively occurred. The AE signal generated during application of PII5 and PII6 is depicted in Fig. 3e and Fig. 3f with the contrast is 6321 events. It means that even though small crack occurred, the energy released by the stress would trigger lots of AE signals. It indicates that $\mathrm{AE}$ is capable of detecting any change or deformation that occurred in the beam specimen. Fig. $3 \mathrm{f}$ and Fig. $3 \mathrm{~g}$ shows the AE characteristic when the beam specimen subjected to $0.7 \mathrm{P}_{\text {ult. }}$ It is found that the AE generates low signal when repeating load was applied on the beam specimen.

\section{Conclusion}

No crack was observed when load based on $\mathrm{P}_{\text {cr }}$ was applied on the precast $\mathrm{RC}$ beam specimens. The first flexural crack was observed at the mid-span when $0.2 \mathrm{P}_{\text {ult }}$ was applied on the beam. The concentration of the crack was found at the area of within the beam supports. It was found that the duplication of load produces little increment of cracks. The AE characteristics based on the relationship between signal strength and X-location were found dependent upon the load application. A significant increase of AE signals were noticed as the load applied on the beam was increased. The AE attributes on the X-location were well matched with the actual crack pattern on the beam surfaces. The duplication of loads produced little increment of the AE activities.

\section{Acknowledgment}

The authors thank Mr. Fakhrul Nazhi Hanaffi (Teraju Construction Sdn. Bhd.), Universiti Teknologi MARA and Ministry of Higher Education, Malaysia.

\section{References}

[1] J. $\mathrm{Xu}$, Nondestructive evaluation of prestressed concrete structures by means of acoustic emissions monitoring, PhD Thesis, Auburn University (2008).

[2] L. Golaski, G. Swit, M. Kalicka, K. Ono, Acoustic emission behavior of prestressed concrete girder during proof loading, J Acoustic Emission, 24 (2006) 187-96.

[3] T. Shiotani, D.G. Aggelis, O. Makishima, Global monitoring of concrete bridge using acoustic emission, J Acoust Emission, 25 (2007), 308-315.

[4] N. Md Nor, A. Ibrahim, N. Muhamad Bunnori, H. Mohd Saman, Acoustic emission signal for fatigue crack classification on reinforced concrete beam, Construction and Building Materials, 49 (2013), 583-590.

[5] N. Md Nor, A. Ibrahim, N. Muhamad Bunnori, H. Mohd Saman, S.N. Mat Saliah, S. Shahidan, Diagnostic of fatigue damage severity on reinforced concrete beam using acoustic emission technique, Engineering Failure Analysis, 41 (2014), 1-9.

[6] C.K. Shield, Comparison of acoustic emission activity in reinforced concrete and prestressed concrete beams under bending, Construction and Building Materials, 11 (3), (1997) 189-194.

[7] E. ASTM 1316, Standard terminology for nondestructive examination, ASTM International (2006).

[8] P.H. Ziehl, Development of a damage based design criterion for fibre reinforced vessel, Phd Thesis, The University of Texas, (2000).

[9] J.C. McCormac, J.K. Nelson, Design of reinforced concrete, ACI 318-05 Code edition (2006). 